\title{
Ankyrin Mutations in Hereditary Spherocytosis
}

\author{
Archana M. Agarwal \\ University of Utah Health, Department of Pathology/ARUP Laboratories, Salt Lake City, UT, USA
}

\section{Keywords}

Anemia $\cdot$ Hereditary spherocytosis $\cdot$ Ankyrin .

Next-generation sequencing

Hereditary spherocytosis (HS) is the most common cause of inherited red cell membrane disorders and affects approximately 1 out of every 2,000-5,000 people. Although seen in all ethnicities, it is more common in people from northern European ancestry. Clinical presentation is variable, ranging from asymptomatic to severe form of anemia, and can be exacerbated by pregnancy, sudden blood loss, or superimposed infection, i.e., parvovirus that targets the erythroid precursors. Some patients, who later on develop only mild or moderate anemia, can present with severe transfusion-dependent anemia in the neonatal period due to ineffective erythropoiesis as well as increased splenic function immediately after birth [1]. Due to marked hemolysis leading to increased bilirubin levels, these infants are prone to acute bilirubin encephalopathy, also known as kernicterus. Moreover, the diagnosis can be challenging in the neonatal period due to unreliability of biochemical tests like osmotic fragility and eosin- $5^{\prime}$ maleimide if age-appropriate controls are not used. Furthermore, spherocytosis due to other causes, i.e., $\mathrm{ABO}$ incompatibility, can also confound some of these tests that rely mainly on the presence of spherocytes for diagnosis.

\section{KARGER}

() 2019 S. Karger AG, Basel

E-Mail karger@karger.com

www.karger.com/aha
Editorial comment on the paper by Luo et al. Spectrum of Ankyrin Mutations in Hereditary Spherocytosis: A Case Report and Review of the Literature. Acta Haematol 2018;140(2):77-86.

Mutations in ankyrin gene (ANK1) is the most common cause of HS in Northern European populations but is seen in only $5-10 \%$ of Japanese patients. The majority of them are familial mutations inherited in an autosomal dominant form. Autosomal recessive mutations have been described and they usually represent the de novo mutations. Ankyrin protein has a binding site for band 3 that links beta-spectrin to band 3 , and the deficiency of ankyrin protein leads to a decrease in spectrin assembly on the membrane, ultimately leading to membrane loss [2]. No homozygous mutation has been described; however, a possibility of mild homozygous or compound homozygous mutations mimicking a de novo pattern cannot be ruled out for certainty [3, 4]. Mutations have been described all along the ANK1 gene, frameshift and nonsense mutations are mainly seen in patients with autosomal dominant inheritance, and missense mutations and promoter site mutations are mainly seen in the autosomal recessive form of HS [4]. Other commonly mutated genes in HS are SPTB, SLC4A1, EPB42 and SPTA1, which encode beta-spectrin, band-3, protein 4.2 , and alpha-spectrin, respectively.

Next-generation sequencing (NGS) provides a comprehensive and cost-effective approach to molecular diagnosis of hereditary hemolytic anemia, especially in cases where biochemical testing is unreliable due to multiple transfusions. This technology has been used successfully

Archana M. Agarwal

University of Utah/ARUP Laboratories 500 Chipeta Way

Salt Lake City, UT 84108 (USA)

E-Mail archana.agarwal@hsc.utah.edu 
to determine the molecular basis of HS in complex scenarios, i.e., autosomal recessive with lack of family history or in neonatal period with severe anemia leading to multiple transfusions [5].

In an earlier issue of Acta Haematologica, Luo et al. [6] reported a novel ankyrin mutation using NGS and have reviewed the relevant literature focusing on the pediatric/ neonatal population. The propositus is a female neonate who presented with total bilirubin of $65 \mu \mathrm{mol} / \mathrm{L}$ and direct bilirubin of $19.4 \mu \mathrm{mol} / \mathrm{L}$. In the following 3 days, her hemoglobin level went down from 11 to $6.7 \mathrm{~g} / \mathrm{dL}$, with a high mean corpuscular hemoglobin concentration of $372-384 \mathrm{~g} / \mathrm{L}$ with an elevated reticulocyte count of $4.3 \%$. Her mother has had jaundice, anemia, and splenomegaly for 17 years. The father of the propositus was clinically normal. NGS and Sanger sequencing revealed a splicing ANK1 mutation (c.2960+2T>G) in both the patient and her mother. No mutation was detected in the father. This appears to be a novel pathogenic splice site mutation. Although definitive confirmation of pathogenicity of a splice site variant requires functional analysis by either
RNA or protein, it would be fair to assume that this variant is likely pathogenic based on these criteria: (a) according to American College of Medical Genetics standard and guidelines for the interpretation of sequence variants, this variant will be regarded as PVS1 null variant due to the site of the mutation, i.e., canonical +2 splice site; (b) the molecular defects matched the HS phenotype in the family; (c) another HS-causing mutation described in the literature [5] at c.2960+1G $>$ A.

Luo et al.'s study [6] not only reports a novel splice site mutation in ANK1 gene, it also emphasizes the utility of NGS in the diagnosis of these complex multigene disorders. Identifying the underlying genetic cause not only helps with the management of the patient, it also facilitates accurate genetic counselling and helps in guidance regarding the predicted severity of clinical phenotype.

\section{Disclosure Statement}

No conflicts of interest to disclose.

\section{References}

1 Delhommeau F, Cynober T, Schischmanoff PO, Rohrlich P, Delaunay J, Mohandas N, et al. Natural history of hereditary spherocytosis during the first year of life. Blood. 2000 Jan; 95(2):393-7.

2 Peters LL, Lux SE. Ankyrins: structure and function in normal cells and hereditary spherocytes. Semin Hematol. 1993 Apr;30(2):85118.
3 Delaunay J. The molecular basis of hereditary red cell membrane disorders. Blood Rev. 2007 Jan;21(1):1-20.

4 Eber SW, Gonzalez JM, Lux ML, Scarpa AL, Tse WT, Dornwell M, et al. Ankyrin-1 mutations are a major cause of dominant and recessive hereditary spherocytosis. Nat Genet. 1996 Jun;13(2):214-8.
5 Agarwal AM, Nussenzveig RH, Reading NS, Patel JL, Sangle N, Salama ME, et al. Clinical utility of next-generation sequencing in the diagnosis of hereditary haemolytic anaemias. Br J Haematol. 2016 Sep;174(5):806-14.

6 Luo Y, Li Z, Huang L, Tian J, Xiong M, Yang Z. Spectrum of ankyrin mutations in hereditary spherocytosis: a case report and review of the literature. Acta Haematol. 2018;140(2): 77-86. 